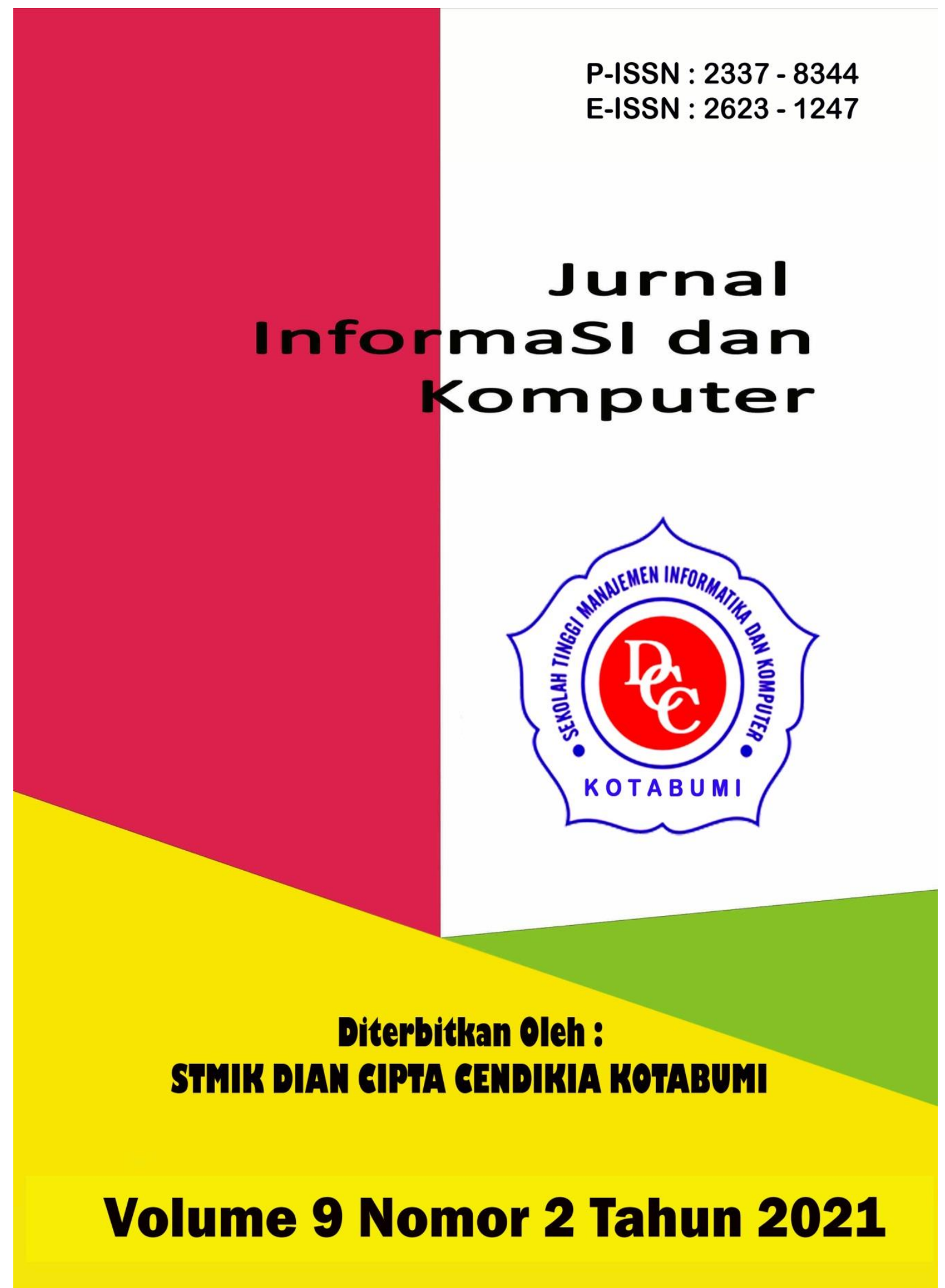




\section{Penerbit}

\section{Lembaga Penelitian STMIK Dian Cipta Cendikia Kotabumi}

Hak atas naskahh/tulisan tetap berada pada penulis, isi diluar tangung jawab penerbit dan Dewan Penyunting 


\section{PENGANTAR REDAKSI}

Puji syukur dipanjatkan kehadirat Tuhan Yang Maha Esa, atas karunia dan limpahan rahmatNYA jualah Jurnal Informasi dan komputer (JIK) STMIK Dian Cipta Cendikia Kotabumi ini dapat terwujud.Jurnal Informasi dan Komputer (JIK) yang terbit dua (2) kali dalam setahun ini merupakan suatu wadah untuk penyebar luasan hasil-hasil penelitian, studi pustaka, karya ilmiah yang berkaitan dengan Informasi dan Komputer khususnya bagi dosen-dosen STMIK Dian Cipta Cendikia Kotabumi serta umumnya para cendikiawan, praktisi, peneliti ilmu Informatika dan Komputer.

Harapan, dengan diterbitkannya Jurnal Informasi dan Komputer (JIK) ini sebagai salah satu bentuk sumbangan pemikiran dalam pengembangan ilmu informatika dan komputer yang berkaitan dengan kajian-kajian di bidang tekhnologi Informatik, Komunikasi Data dan Jaringan Komputer, perancangan dan Rekayasa Perangkat Lunak, serta ilmu-ilmu yang terkait dengan bidang Informasi dan Komputer lainnya.

Berkenaan dengan harapan tersebut, kepada para peneliti, dosen dan praktisi yang memiliki hasil-hasil penelitian, kajian pustaka, karya ilmiah dalam bidang tersebut diatas, dengan bangga redaksi Jurnal Informasi dan Komputer (JIK) menerima naskah ringkasan untuk dimuat pada jurnal Informasi dan Komputer (JIK) STMIK Dian Cipta Cendikia Kotabumi dengan berpedoman pada penulisan naskah jurnal sebagaimana dilampirkan pada halaman belakang (Bagian kulit dalam) buku jurnal ini.

Mutu dari suatu jurnal ilmiah tidak hanya ditentukan oleh para pengelolanya saja, tetapi para penulis dan pembaca jualah yang mempunyai peranan besar dalam meningkatkan mutu jurnal Informatika dan Komputer ini. Merujuk pada realita ini kamu sangat mengharapkan peran aktif dari peneliti untuk bersama-sama menjaga dan memelihara keberlangsungan dari jurnal Informasi dan Komputer STMIK Dian Cipta Cendikia Kotabumi ini. Yang juga tidak kalah pentingnya dari partisipasi tersebut diatas, adalah saran dan kritik yang membangun dari pembaca yang budiman agar kiranya dapat disampaikan langsung kepada redaksi JIK. Saran dan kritik yang membangun akan dijadikan masukan dan pertimbangan yang sangat berarti guna peningkatan mutu dan kualitas Jurnal Informasi dan Komputer STMIK Dian Cipta Cendikia Kotabumi.

Tak lupa diucapkan terima kasih yang tak terhingga atas perhatian dan kerjasama dari semua pihak yang tak dapat disebutkan satu persatu hingga dapat diterbitkan nya Jurnal Informasi dan Komputer (JIK) STMIK Dian Cipta Cendikia Kotabumi. Semoga apa yang telah diperbuat untuk kebaikan akan menjadi amal ibadah, amin.

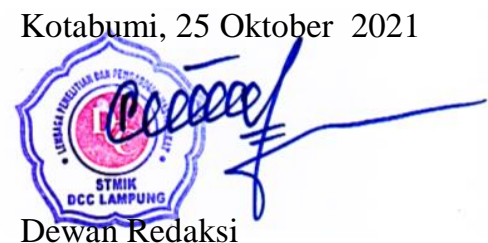




\section{JURNAL INFORMASI DAN KOMPUTER}

Volume 9 Nomor 2 Oktober 2021

Jurnal Informasi dan Komputer merupakan Sarana informasi ilmu pengetahuan, Tekhnologi dan Komunikasi yang berupa hasil penelitian, tulisan ilmiah, Ataupun studi pustaka. Jurnal ini terbit dua kali setahun pada bulan April dan Oktober. Berisi hasil penelitian ilmiah di bidang informatika yang bertujuan untuk menghubungkan adanya kesenjangan antar kemajuan teknologi dan hasil penelitian. Jurnal ini di terbitkan pertama kali pada tahun 2013.

Penanggung Jawab:

Ketua STMIK Dian Cipta Cendikia Kotabumi

\section{Pembina:}

Ketua STMIK Dian Cipta Cendikia Kotabumi Ketua Lembaga Penelitian STMIK Dian Cipta Cendikia Kotabumi

\section{Pimpinan Redaksi}

Dwi Marisa Efendi,.S.Kom.,M.Ti

\section{Redaksi pelaksana}

Rustam,.S.Kom,.M.Ti (STMIK Dian Cipta Cendikia Kotabumi)

Nurmayanti M.Kom (STMIK Dian Cipta Cendikia Kotabumi)

Sukatmi,.S.Kom., M.Kom (AMIK DCC Bandar Lampung)

Sampurna Dadi Riskiono,M.Kom (Universitas Teknokrat Indonesia)

Ifo Wahyu Pratama,S.Kom.,M.Ti(AMIK MASTER Lampung)

\section{Mitra Bestari}

Dr. RZ. ABDUL AZIZ, ST., MT (Institut Informatika dan Bisnis Darmajaya)

Dr. Dadang Sudrajat, S.Si, M.Kom (STMIK IKMI Cirebon)

Dr. Septafiansyah Dwi Putra, S.T., M.T (Politeknik Negeri Lampung)

Dr. Evi Grativiani, S.E., M.S.I (Universitas Sebelas Maret)

Rohmat Indra Borman ( Universitas Teknokrat Indonesia )

Ferry Wongso, S.KOm., M.Kom ( STMIK Darma Pala Riau)

Ferly Ardhy, S.Kom., M.Ti ( Universitas Aisyah Pringsewu )

Firmansyah, S.E., M.Si (STMIK Darma Pala Riau)
Amarudin (Universitas Teknokrat Indonesia)

Didi Susianto, S.T., M.Kom (AMIK Dian Cipta Cendika Bandar Lampung)

Alhibarsyah, St., M.Kom (STMIK Tunas

Bangsa Bandar Lampung)

Kemal Farouq Mauladi, S.Kom .M.Kom (Universitas Islam Lamongan)

Rima Mawarni, M.Kom ( STMIK Dian Cipta Cendikia Kotabumi)

Wira Jaya Hartono, S.Pd., M.Pd ( STMIK Darma Pala Riau)

Penerbit : STMIK Dian Cipta Cendikia Kotabumi Bekerja Sama Dengan LPPM STMIK Dian Cipta Cendikia Kotabumi.

\section{Alamat Redaksi/Penerbit:}

Jl. Negara No. 3 Candimas Kotabumi Lampung Utara

No Telpon/Fax 072423003

Email : 1ppm-stmik@dcc.ac.id 


\section{JURNAL INFORMASI DAN KOMPUTER VOL. 9 NO. 2 THN. 2021}

\section{DAFTAR ISI}

\section{Halaman}

Sistem Informasi Akuntansi Persedian Barang Berbasis Web Pada Lembaga

Permasyarakatan Kelas II A Banceuy Bandung : "Kelompok Tani Desa Banjar Kertarahayu” Teuku Rian Hardiyansyah, Fatia Salsa Azzahra (Politeknik Piksi Ganesha Bandung ${ }^{1,2}$ ).

Penerapan Finite State Automata Pada Vending Machine Penjual Obat Non Resep

Dokter Dan Keperluan Medis

Eko Supriyanto $^{1}$, Angga Ardiansyah ${ }^{2}$, Frieyadie $^{3}$, Sri Rahayu ${ }^{4}$, Windu Gata ${ }^{5}$

(Universitas Nusa Mandiri ${ }^{12}$ )

Sistem Pendukung Keputusan Untuk Menentukan Kelayakan Pengajuan Sertifikasi Guru Dengan Metode Simple Additive Weighting (Studi Kasus : Ma Al Muhajirin Janti Jogoroto Jombang)

Budiman, umam baharudin, winarti

(Universitas Darul 'Ulum Jombang)

Perancangan Infrastruktur Domain Name Server Lokal Menggunakan Ubuntu Server 16.04

Pada PT. Xyz

Zaenal Mutaqin Subekti, Hendra Setiawan, Satria, Widia Murni Wijaya,

Aliy Hafiz, Warsudi

(STMIK Bani Saleh, Universitas Negeri Yogyakarta, AMIK Dian Cipta Cendikia,

STMIK MIC CIkarang).

Perancangan Sistem Informasi Idea Proposal (Ip) Berbasis Web Pada Pt. Paxel Algorita Unggul

Julian Murhan Sahputra, Indah Purnamasari

(Universitas Nusa Mandiri ${ }^{12}$ )

Sistem Pendukung Keputusan Untuk Menentukan Ekstrakurikuler Atletik

Berdasarkan Bakat Siswa Menggunakan Metode Profile Matching

Agnes Basuki, Petrus Sokibi, Tiara Eka Putri

(Universitas Catur Insan Cendekia)

Penerapan Algoritma K-Means Untuk Pengelompokan Usia Calon Penerima Vaksin

Di Kab. Ngawi

Irna Yuniarfi, Saifulloh

(Universitas PGRI Madiun ${ }^{12}$ )

System Penilaian Seleksi Calon Karyawan Baru Menggunakan Metode Simple Additive Weighting (SAW) Di PT.TNA

Anik Sri Wahyuningsih, Yudhi Firmansyah

(Universitas Panca Sakti Bekasi ) 
Perancangan Sistem Informasi Pembayaran SPP Menggunakan Framework Laravel Ichwan Habib Moudi

(Universitas Panca Sakti Bekasi).

Implementasi Algoritma K-Means Dan Algoritma Apriori Optimasi Kinerja Ecu

(Study Kasus Mobil Avanza Dan Xenia)

Sigit Mintoro' Asep Afandi

(STMIK Dian Cipta Cendikia Kotabumi)

Sistem Pakar Penyakit Buah Kakao Untuk Peningkatan Hasil Panen Kakao Menggunakan

Metode Case Base Reasoning (CBR) Berbasis Web Mobile

Aliy hafiz, Verawati

(AMIK Dian Cipta Cendikia,Bandar Lampung).

Penerapan Metode Rapid Application Develomment (RAD) Dalam Pengembangan

Sistem Pemesanan Menu Berbasis Android

Aris Baihaqi, Tumini

(Fakultas Sains dan Teknologi ${ }^{1,2}$ ).....

Rancang Bangun Sistem Informasi Geografis Pariwisata Di Lampung Timur

Sukatmi, Rexa Alfa Rizi

(AMIK DCC Bandar Lampung ${ }^{12}$ )

Implementasi Psak No. 45 Pada Proses Penyusunan Laporan Keuangan Menggunakan

M.S. Excel Dan Aplikasi Accurate Accouting Pada STMIK Bani Saleh

Marhakim, Willy Adam

$\left(\right.$ STMIK Bani Saleh ${ }^{12}$ )

Sistem Prediksi Harga KOPI LAMBAR ( Lampung Barat) Dengan Metode

Backpropagation, dan Double Exponential ( Studi Kasus BUMDES )

Supriyanto, Dwi marisa Efendi,Rhomadhon

(STMIK Dian Cipta cendikia Kotabumi ${ }^{1-}$ )

Sistem Informasi Pemasaran Produk Umkm Berbasis Web Pada Kecamatan Bumi

Nabung Lampung Tengah

Yuli Syafitri, Agus Prasetyo, Reni Astika

(AMIK Dian Cipta Cendikia Bandar Lampung)

Rancang Bangun Aplikasi Pembelajaran Aksara Lampung Berbasis Android

Ferly Ardhy, Hendra Syahrobi

(Universitas Aisyah Pringewu ${ }^{1,}$ STMIK Dian Cipta Cendikia ${ }^{2}$ )

Sistem Pakar Diagnosa Penyakit Kulit Pada Balita Menggunakan Metode Naïve

Bayes Dan Forward Chaining Studi Kasus Puskesmas Cempaka Sungkai Selatan

Sidik Rahmatullah, Rima Mawarni

(STMIK Dian Cipta Cendikia Kotabumi ${ }^{12}$ )

Rekayasa Perangkat Lunak Perhitungan Harga Pokok Produksi Metode

Full Costing Pada Umkm Mitra Cake Di Bandar Lampung

Pitrawati, Arif Sanjaya

(AMIK Dian Cipta Cendikia, Bandar Lampung) 
Rancang Bangun Sistem Ujian Online Menggunakan Algoritma Cosine Similarity

Berbasis Web

Haryono, Zaenal Mutaqin Subekti, Widiyawati, Hidayatullah

(STMIK Bani Saleh ${ }^{1234}$ )

Model Aplikasi Helpdesk Ticketing System Berbasis Web Menggunakan Metode Rad

Indra Permana

Pattern Recognition Tulisan Tangan Huruf Hijaiyah Menggunakan Metode

Convolutional Neural Network (CNN)

Mufassiril Abror, Nopiyanto

(Universitas Panca Sakti Bekasi ${ }^{12}$ )

Aplikasi Sistem Informasi Keuangan Berbasis Android Di Perumahan Taman

Karang Bahagia

Melda Ayulestari

(Universitas Panca Sakti Bekasi)

Audit Pelayanan Sistem Rujukan Online Puskesmas Menggunakan Framework COBIT 5.0

Nurmayanti, Merri Parida, Ngajiyanto, Ina Anzalna

(STMIK Dian Cipta Cendikia Kotabumi ${ }^{1234}$ )

Perancangan Sistem Informasi Pengolahan Data Nilai Siswa Berbasis Web

Erin Ermawati, Anik Sri Wahyuningsih

(Fakultas Sain dan Teknologi, Universitas Panca Sakti Bekasi ${ }^{12}$ )

Pengembangan Sistem Pelaporan Data Hasil Inspeksi Barang Berbasis Web

Siska Putriani

(Universitas Pancasakti Bekasi)

Penerapan Extreme Programming Dalam Perancangan Aplikasi Web Food Market

Tumini, Hilman Septiana

(Fakultas Sains dan Teknologi Universitas Panca Sakti Bekasi ${ }^{1,2}$ )

Sistem Pencarian Barang Berbasis Website Menggunakan Php Dan Mysql

Studi Kasus PT. Surya Technology Industri Sulaeman

(Universitas Panca Sakti Bekasi)

Implementasi Metode Prototype Pada Sistem Peminjaman Alat Kerja Berbasis Web

Di PT SK Metalindo

Ali Mulyanto, Arjun Gunawan

(Univeritas Panca Sakti Bekasi)

Aplikasi Tata Cara Wudhu Menggunakan Teknologi Augmented Reality

Sebagai Media Pembelajaran Di TK Al Fatih

Ahmad Yakub, Idarul Fadli

(Universitas Panca Sakti Bekasi ${ }^{12}$ )

Sistem Pakar Diagnosa Penyakit Ayam Petelur Menggunakan Metode Certainty Factor

Berbasis Web Mochammad

Taufiq Hidayat, Ali Mulyanto

(Universitas Panca Sakti Bekasi ${ }^{12}$ ) 
Penerapan Metode Prototyping Dalam Perhitungan Hasil Produksi Menggunakan

Arduino Uno R3 Dan Php Di PT. Indonesia Epson Industry

Amandha Aulia, Ajar Rohmanu

(Universitas Panca Sakti Bekasi ${ }^{12}$ )

System Pendukung Keputusan Penentuan Guru Teladan Dengan Metode Profile Matching

Hasbulloh, Agmawarnida

(Universitas Panca Sakti Bekasi ${ }^{1,2}$ )

Implementasi Waterfall Method Pada Aplikasi Buku Induk Siswa Berbasis Web

Idam Holid, Yogie Krisnayadi

(Universitas Panca Sakti ${ }^{12}$ )

Pengembangan Text To Speech Media Pembelajaran Untuk Pengenalan

Anggota Tubuh Manusia Kelas V Sekolah Dasar

Juwanda Saputra, Ali Mulianto

(Teknik Infomratika Fakulutas Sains dan Teknologi ${ }^{12}$ )

Perancangan Sistem Peminjaman Barang Berupa Aset Tetap Berbasis Web

Pada Lembaga Permasyarakatan Kelas II A Banceuy Bandung

Guntur Salasa Priambodo, Perwito, Candra Mecca Sufyana

(Politeknik Piksi Ganesha Bandung ${ }^{1,2,3}$ )

Metode Pemilihan Karyawan Terbaik Sebagai Penentu Goodwill Perguruan Tinggi

Dengan Menggunakan Metode Topsis (Studi Kasus Perguruan Tinggi Di Lampung Utara)

Dwi Sartika, Pakarti Riswanto

(STMIK Dian Cipta Cendikia Kotabumi)

Sistem Pendukung Keputusan Pemilihan Merek Smartphone Menggunakan

Metode Analytical Hierarchy Process (AHP)

Ade Kiki Fatmawati, Muhammad Sultan Raflie, Norma Yunita

(Universitas Nusa Mandiri ${ }^{123}$ )

Pattern Recognition Aksara Lampung Menggunakan Algoritma Neural Network

Metode Analytical Hierarchy Process (AHP)

Nopiyanto, Rahmadi

(Universitas Panca Sakti Bekasi) 


\title{
SISTEM INFORMASI PEMASARAN PRODUK UMKM BERBASIS WEB PADA KECAMATAN BUMI NABUNG LAMPUNG TENGAH
}

\author{
Yuli Syafitri ${ }^{1}$, Agus Prasetyo ${ }^{2}$, Reni Astika ${ }^{3}$ \\ AMIK Dian Cipta Cendikia Bandar Lampung \\ Jl. Cut Nyak Dien No. 65 Durian Payung (Palapa) Bandar Lampung \\ E-mail: ayulisyafitri@gmail.com ${ }^{1}$,aguspras137@gmail.com ${ }^{2}$, astikareni@gmail.com ${ }^{3}$
}

\begin{abstract}
ABSTRAK
Usaha Mikro Kecil dan Menengah (UMKM)merupakan sekelompok pelaku Terbesar dalamperekonomian dan terbuktisebagi pondasi, tulang punggung dan penggerak perkembangan perekonomian nasional, terutama ketika masa krisis dan perlambatan pertumbuhan ekonomi Indonesia, dan adapun pemasaran yaitu proses mengidentifikasi sesuatu hal, menghasilkan dan menyampaikan nilai, dan menjaga hubungan yang baik dan memuaskan konsumen untuk mengoptimalkan keuntungan suatu usaha. Permasalahan pokok yang menjadi latar belakang penelitian ini kurangnya pemanfaatan internet dalam proses pemasaran produk-produk UMKM sehingga tujuan dari pemasaran dan penjualan sulit dicapai. perancangan serta membangun sebuah sistem pemasaran produk-produk UMKM secara online dengan berbasis website mempergunakan bahasa pemograman php, html, css, javascript dan bahasa pemograman pendukung lainya, serta menggunakan media penyimpanan data atau basis data MYSQL sangat diperlukan saat ini. Metode penelitian yang digunakan dalam melakukan pembangunan sistem pemasaran ini menggunakan metode pengembangan sistem Extreme Programming. Sehingga diharapkan penelitian ini dapat menghasilkan sebuah karya tulis ilmiah yang berisi analisa dan perancangan dan sebuah sistem pemasaran produk UMKM online berbasis web yang mampu menyelesaikan permasalahan yang dirumuskan terutama menjadi solusi pemasaran produk UMKM yang luas dengan memanfaatkan internet sehingga tujuan pemasaran dan penjualan dapat dicapai serta memakmurkan pelaku UMKM pada daerah penelitian terkait.
\end{abstract}

Kata kunci : Usaha Mikro Kecil dan Menengah (UMKM), Pemasaran, Internet

\begin{abstract}
Micro, Small, and Medium Enterprises (MSMEs) are a group of actors. the largest in the economy and proven to be the foundation, backbone, and driver of the development of the national economy, especially during times of crisis and slowing growth in the Indonesian economy, and as for marketing, namely the process of identifying something, producing and. .deliver.value, and.maintain..good relationship and satisfy consumers.to optimize. profit.a business. The main problem that becomes the background of this research is the lack of use of the internet in the process of marketing MSME products so that the objectives of marketing and sales are difficult to achieve. designing and building an online marketing system for MSME products based on a website using programming languages. PHP, HTML, .css, javascript, and other supporting programming languages, as well as using data storage media or databases. MYSQL is very necessary currently...Method.research..used..in doing development..this marketing system..using..development method.Extreme Programming system. So it is hoped that this research can produce a scientific paper that contains analysis and design and a web-based online MSME product marketing system that can solve problems that are formulated primarily as a broad MSME product marketing solution by utilizing the internet so that marketing and sales goals can be achieved and prosper. SMEs in the related research areas.
\end{abstract}

Keywords: Micro, Small and Medium Enterprises (MSMEs), Marketing, Internet 


\section{PENDAHULUAN}

\subsection{Latar Belakang}

Semakin maju telekomunikasi, teknologi informasi, dan internet saat ini mulai mengubah kehidupan masyarakat untuk masuk kedalam sebuah era dunia yang modern, contoh dari suatu bentuk modernisasi yang mulai berkembang yaitu dengan pemanfaatan teknologi internet dalam ranah bidang industri dan perdagangan (transaksi jual dan beli), pada mulanya transaksi jual beli hanya dilakukan dengan cara konvensional yaitu masih terhalang dengan batas ruang dan waktu, sejalan dengan peningkatan jumlah pelaku dan kemudahan untuk mengakses internet, perdagangan yang menggunakan cara lama mulai dikembangkan menjadi perdagangan secara elektronik, dimana para pelaku dapat melakukan transaksi tanpa terbatas teritori ruang (geografis) dan waktu.

Banyak perusahaan berskala besar sudah menerapkan teknologi internet dalam perdagangan namun hal tersebut masih sukar dilakukan oleh perusahaan yang berskala mikro, kecil dan menengah atau yang biasa disebut UMKM, karena besarnya modal awal yang harus dikeluarkan dan juga kurangnya pengetahuan tentang penerapan teknologi internet dibidang perdagangan oleh pelaku. UMKM punya peran penting dalam konstruksi ekonomi nasional, baik dari penyerapan tenaga kerja ataupun kesejahteraan seluruh masyarakat didaerah. Maka perlu adanya pengembangan dan mewujudkan langkah baru untuk lebih fokus dalam mengembangkan pola kegiatan UMKM di-Indonesia untuk mencapai perekonomian yang lebih baik lagi.

Dari latar belakang yang sudah dipaparkan diatas, sistem pemasaran online bisa dimanfaatkan sebagai solusi efisien untuk membantu UMKM melakukan perluasan pasar dan peningkatan penjualan serta mampu berperan aktif dalam pemanfaatan teknologi internet dibidang perdagangan. Untuk meningkatkan kenyamanan dalam bertransaksi, diterapkan cara pembayaran non tunai atau menggunakan transfer, sehingga bisa meningkatkan kenyaanan pembeli dalam melakukan transaksi.

\subsection{Referensi}

\subsubsection{Pengertian Sistem Informasi}

Pada umumnya permasalahan sistem informasi selalu ditekankan pada bagaimana cara dalam menghasilkan sebuah informasi, dan data apa yang harus dilengkapi untuk sumber yang akurat.

"Sistem informasi adalah cara-cara yang di organisasi untuk mengumpulkan, memasukkan, dan mengolah serta menyimpan data ,dan cara yang diorganisasi untuk menyimpan, mengelola, mengendalikan, dan melaporkan informasi sedemikian rupa sehingga sebuah organisasi dapat mencapai tujuan yang telah ditetapkan". ( Krismiaji 2015:15

"Sistem Informasi adalah kumpulan elemenelemen atau sub sistem yang disatukan yang saling berkaitan atau berhubungan untuk mengelola data sehingga menjadi berarti bagi penerima dan bermanfaat untuk pengambilan keputusan di saat ini atau di masa yang akan datang". ( Anggun Nugroho $2015: 974$ )

Dari pengertian diatas dapat dijabarkan bahwa sistem informasi ialah kombinasi dari manusia, hardware, software, jaringan komunikasi dan data yang saling berinteraksi untuk menyimpan, mengumpulkan, mengelola, serta mendistribusikan informasi dalam mendukung pengambilan keputusan pada suatu organisasi.

\subsubsection{Pengertian Pemasaran}

Pemasaran merupakan suatu proses sosial yang berisi aktifitas yang dilakukan untuk mengaktifkan individuals dan organisasi agar memperoleh tujuan yang mereka inginkan serta menarik minat dari konsumen untuk membeli barang yang mereka pasarkan.

"Pemasaran mengidentifikasi sesuatu, menciptakan dan mengkomunikasikan nilai, serta memelihara hubungan yang memuaskan pelanggan untuk memaksimalkan keuntungan perusahaan". ( Ali \& Hasan, 
2015 )

"Pemasaran adalah proses sosial dan manajerial dimana individu dan kelompok memenuhi kebutuhan dan keinginan mereka dengan menciptakan, menawarkan, dan bertukar sesuatu yang bernilai dengan pihak lain". ( Kotler \& Amstrong 2018:3 )

Dari pengertian diatas disimpulkan Pemasaran yaitu suatu proses sosial yang berisi aktifitas yang dilakukan untuk mengaktifkan individuals dan organisasi agar memperoleh tujuan yang mereka inginkan serta menarik minat dari konsumen untuk membeli barang yang mereka pasarkan. Jadi disimpulkan bahwa pemasaran adalah suatu proses sosial atau fungsi organisasi dalam aktifitas bisnis dengan maksud untuk menyalurakan atan mendistribusikan barang-barang dalam rangka mencari keuntungan.

\subsubsection{Pengertian Sistem Informasi Pemasaran}

"Sistem informasi pemasaran diartikan sebagai bagian-bagian yang saling berhubungan dan saling berkaitan secara tetap dalam membentuk suatu kesatuan terpadu yang erat hubunganya terhadap organisasi, perusahan, jasa, barang, ide-ide, orang, target, faktor- faktor lingkungan, teknologi yang saling mempengaruhi kondisi dan keadaan pasar". (Haryantini,Agra Sadya 2019:4)

Sistem informasi pemasaran adalah rangkaian yang mengatur perusahaan terutama dalam menyelesaikan bidang pemasaran perusahaan dengan terkomputerisasi. Selain itu sistem yang memberikan informasi untuk penjualan, promosi produk, aktifitasaktifitas pemasaran, kegiatan-kegiatan penelitian pasar, konsumen dan lainya yang berkaitan dengan pemasaran. Jadi bisa disimpulkan Sistem informasi pemasaran (Marketing Information Sistem) atau MKIS adalah suatu sistem berbasis digital yang berintraksi dengan sistem fungsional yang lain guna mendukung manajemen perusahaan dalam solusi masalah yang berkaitan dengan pemasaran barang perusahaan.

\subsubsection{Pengertian UMKM}

Usaha Mikro Kecil dan Menengah (UMKM) merupakan sekelompok pelaku ekonomi terbesar dalam perekonomian dan terbukti sebagi pondasi, tulang punggung dan penggerak perkembangan perekonomian nasional, terutama ketika masa krisis dan perlambatan pertumbuhan ekonomi Indonesia.

Usaha Mikro Kecil Menengah (UMKM) bertujuan menciptakan dan mengembangkan usahanya dalam rangka membangun perekonomian nasional berdasarkan demokrasi ekonomi yang berkeadilan. Secara konseptual pemberdayaan Usaha Mikro Kecil Menengah (UMKM) bisa diwujudkan dengan sistem pemberdayaan mitra Usaha Mikro Kecil Menengah (UMKM) itu sendiri. Keberhasilan pemberdayaan tersebut sangat dipengaruhi pada ikut serta Usaha Mikro Kecil Menengah (UMKM) sebagai pelaku maupun stakeholder lain yang turut serta dan berperan dalam pengembangannya. ( UU No. 20 Tahun 2008 pasal 3 )

\subsubsection{Pengertian Website}

Situs web (Website) merupakan salah satu sistem yang terdiri dari dokumen digital (teks, gambar, suara, animasi, video) didalamnya dengan menerapkan protokol HTTP (Hypertext Transfer Protocol) dan untuk pengaksesanya dengan perangkat lunak yang disebut web browser.

"Website adalah halaman informasi yang disediakan melalui jalur internet sehingga bisa diakses diseluruh dunia, selama terkoneksi dengan jaringan internet". ( Kesuma \& Rahmawati 2017:3)

Berdasarkan pengertian tersebut bisa menyimpulkan bahwa Website merupakan sistem yang terdiri dari dokumen multimedia teks, gambar, suara, animasi, video dan yang dapat diakses dengan perangkat yang tersambung dengan internet. 


\subsubsection{Pengertian Sistem Operasi}

Sistem Operasi atau sering disingkat OS merupakan system software yang menjalankan kontrol pengaturan perangkat keras dan fungsi pokok sistem dalam komputer. OS juga mengatur untuk menjalankan perangkat lunak seperti aplikasi atau program yang terinstal didalamnya.

"Sistem operasi merupakan sebuah sistem yang terdiri dari beberapa komponen software atau perangkat lunak yang mempunyai fungsi untuk mengontrol semua kegiatan yang telah dilakukan oleh komputer". (M.Suyatno 2015,9)

\subsubsection{Pengertian Web Server}

"Web Server adalah sebuah software yang berfungsi untuk menerima dan melayani permintaan yang dikirimkan user melalui browser kemudian ditampilkan kepada user sesuai dengan permintaan yang dikirimkan ke server". ( A Tedyyana \& Kurniati 2016,35 )

Dapat disebut web server adalah pusat kendali yang berfungsi untuk mengolah permintaan yang diterima dari browser. Layanan ini juga dapat merujuk sebagai software atau hardware contohnya Xampp, Nginx, LiteSpeed.

\subsubsection{Pengertian Code Editor}

"Code Editor adalah suatu software aplikasi atau suatu program komputer yang memungkinkan kalian sebagai penggunanya untuk membuat, mengubah atau mengedit file teks yang ada berupa text biasa". (Elisabet Yunaeti Anggraeni dan Rita Irviani 2017 : 12)

Code editor ini umumnya dapat digunakan dalam membuat program komputer atau mengedit source code dari bahasa pemograman. Dan juga code editor dapat dimanfaatkan dalam membuat halaman web atau template web design dan membuat program tertentu. Software yang satu ini memang pada umum dimaksudkan dalam mempermudah kegiatan pemrograman. Contohnya adalah Notepad++, Dreamweaver, SublimText.

\section{METODE PENELITIAN}

Pada penelitian ini menggunakan metode pengembangan sistem Extreme Programming (XP). Metode pengembangan sistem Extreme Programming (XP) ini adalah suatu langkah kerja atau model pengembangan perangkat lunak yang terorganisir menyederhanakan setiap langkah dalam proses pengembangan sistem tersebut, alhasil menjadi lebih adaptif dan luwes, lebih cenderung menggunakan pendekatan yang berorientasi objek dan sasaran dari metode ini adalah tim yang dibentuk dalam skala kecil sampai medium, sehingga metode extreme programming (XP) lebih mengutamakan proses pengembangan yang lebih adaptif terhadap kebutuhan.

"Extreme Programming (XP) adalah sebuah pendekatan atau model pengembangan perangkat lunak yang mencoba menyederhanakan berbagai tahapan dalam proses pengembangan tersebut sehingga akan menjadi lebih adaptif dan fleksibel". (M Alda 2021,34) Tahapannya sebagai berikut :

\section{Planning}

Pada tahap ini developer harus mengumpulkan seluruh informasi data untuk kebutuhan sistem seperti kegunaan sistem yang dimaksud oleh pengguna dan melakukan perencanaan gambaran sistem yang akan dibuat.

\section{Design}

Sebelum coding perlu adanya desain. Ini dimaksudkan sebagai gambaran menyeluruh tentang apa yang akan dikerjakan dan bagaimana interface dari sebuah sistem yang akan dibuat.

\section{Coding}

Pada tahapan ini dilakukan penulisan code dan penyatuan dari modul-modul yang telah dibuat.

\section{Testing}

Setelah tahapan coding akan dilakukan pengujian yang dimaksudkan untuk mengetahui apakah sistem telah sesuai dengan 
yang diharapkan dan apakah masih ada permasalahan atau tidak.

\section{Implementation}

Implementasi merupakan tahap penerapan dan juga sekaligus uji coba bagi sistem berdasarkan hasil analisa dan perancangan yang telah dilaksanakan ditahapan sebelumnya.

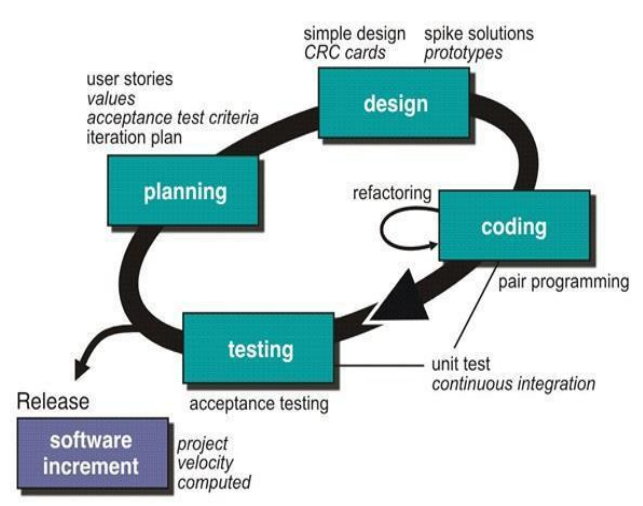

Gambar 1 Tahapan Extreme Programming

\subsection{Alat Pengembangan Sistem}

1. Activity Diagram

Diagram aktivitas

Activity Diagram

atau

langkah kerja atau aktivitas dari sistem pemasaran produk UMKM berbasis web yang akan dibuat atau proses kerja menu yang ada pada perangkat lunak sistem .

2. Class Diagram

Diagram kelas atau Class Diagram menerangkan struktur sistem pemasaran produk UMKM berbasis web yang akan dibuat dari segi deklarasi kelaskelas yang akan ada untuk membangun sistem. Class Diagram adalah rangkaian dari kelas objek.

3. Use Case

Use case menggambarkan suatu interaksi antara satu atau lebih aktor dengan sistem informasi yang akan dibuat. Use Case menerangkan efek kegunaan yang diharapkan ada didalam sistem. Use Case bisa sangat membantu jika kita sedang menyusun kebuthan dari sebuah sistem, dan interaksi sebuah rancangan sistem dengan pengguna.

\subsection{Teknik Pengumpulan Data}

Untuk mendapatkan data yang dibutuhkan lebih akurat, teknik pengumpulan data digunakan dalam penelitian ini sebagai berikut:

1. Observasi, merupakan aktifitas mengamati dan mencatat kegiatan pemasaran yang dilakukan oleh pelaku UMKM di Kecamatan Bumi Nabung agar dapat diketahui hambatan dan permasalahan nyata yang dihadapi.

2. Studi Keperpustakaan, yaitu dengan mencari referensi yang ada dalam buku, literatur, jurnal, yang ada kaitanya dengan bahasan penelitian.

3. Wawancara, melaksanakan aktifitas tanya jawab pada pelaku usaha atau pelaku UMKM di Kecamatan Bumi Nabung .

\subsection{Analisa Kebutuhan Input}

Kebutuhan input yang diperlukan dalam pembangunan sistem pemasaran online hasil UMKM ini diantaranya :

1. Input data user ( form daftar pembeli dan form daftar penjual)

2. Input autentifikasi ( form login pembeli dan form login penjual)

3. Input data profil lengkap ( form profil pembeli dan form profil penjual)

4. Input bukti transfer (pembeli)

5. Input data produk (penjual)

6. Input no rekening (penjual)

7. Input data pesanan transaksi (pembeli)

\subsection{Analisa Kebutuhan Output}

Kebutuhan output yang diperlukan dalam pembangunan sistem pemasaran online hasil UMKM ini diantaranya :

1. Output detail Transaksi (pembeli)

2. Output Status Pesanan (pembeli)

3. Output detail transaksi (penjual)

4. Output Pesanan masuk (penjual)

5. Output laporan penjualan (penjual)

6. Output bukti transfer (penjual)

\subsection{Analisa Kebutuhan Fungsional}

Untuk mengatasi permasalahan, maka akan dibuat :

1. Sistem mampu menampilkan informasi tentang toko dari penjual, khususnya 
tentang produk yang dijual beserta detailnya.

2. Sistem mampu menunjang promosi penjual umkm.

3. Sistem mampu melayani pemesanan produk secara online.

a) pembeli dapat melakukan transaksi pembelian dan mendapatkan outputnya

b) penjual dapat melakukan pelayanan transaksi pembelian dan menginput barang serta output laporan penjualan.

4. Sistem mampu menghasilkan laporan dan struk

a) pembeli dapat mencetak struk pesanannya.

b) Penjual dapat mencetak struk orderan dan dapat melihat laporan keuanganya.

\subsection{Analisa Kebutuhan Non Fungsional}

\section{Perangkat Keras (Hardware)}

Kebutuhan perangkat keras yang dibutuhkan oleh sistem pemasran online hasil UMKM adalah :
a) Processor intel dual core $2.2 \mathrm{GHz}$
b) Memory RAM minimal $2 \mathrm{~GB} 800 \mathrm{MHz}$
c) Hardisk minimal $250 \mathrm{~GB}$
d) Graphic card Ati Radion 31001 GB
e) Monitor minimal 14 inch
f) Keyboard
g) Mouse
h) Modem/ sambungan internet

\section{Perangkat Lunak (Software)}

Kebutuhan perangkat Lunak yg dibutuhkan oleh sistem pemasran online hasil UMKM adalah :
a) Sistem Operasi : Microsoft Windows 10
b) Web server : Xampp
c) Code editor : Notepad.++ Ink
d) Web Browser : IE, Opera, Google chrome
e) Script language : html, php, css, dll
f) DBMS : MySQL
g) Framework : Codeigniter dan Bootstrap

\subsection{Rancangan Usecase Diagram}

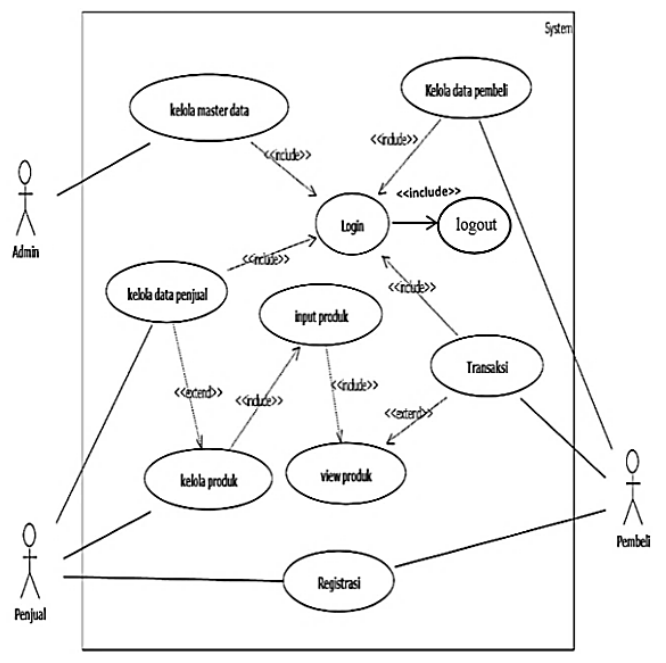

Gambar 2 Rancangan Usecase Diagram

\subsection{Rancangan Class Diagram}

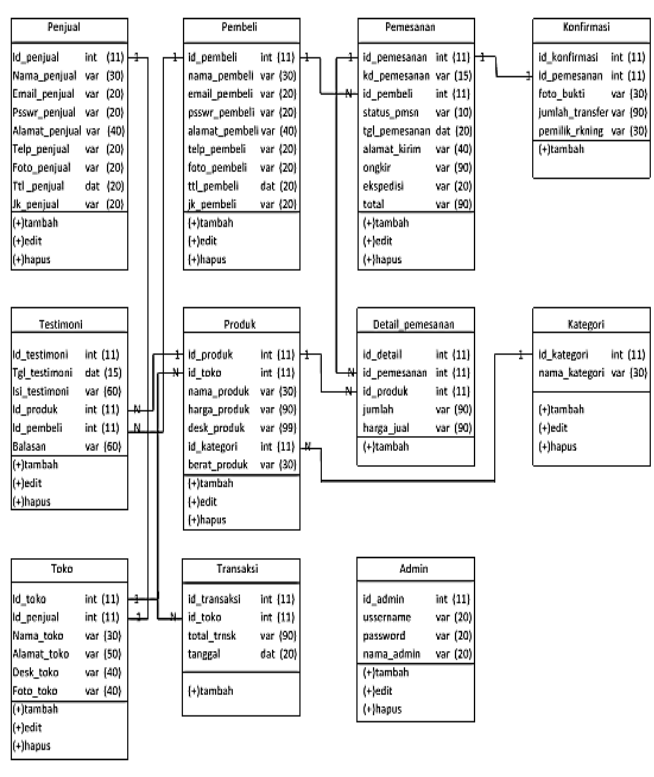

Gambar 3 Rancangan Class Diagram

\section{PEMBAHASAN}

Berdasarkan semua tahapan penelitian yang telah dilakukan mulai dari tahap penganalisaan baik permasalahan dan solusi yang akan diambil, serta telah dilakukanya perancangan dan pembuatan sistem sesuai permasalahan pemasaran produk UMKM terkait, dapat dihasilkan sebuah sistem pemasaran produk UMKM berbasis web yang dapat digunakan untuk memasarkn hasil UMKM Bumi Nabung yg akan memfasilitasi interaksi jual beli antara pelaku umkm dan konsumen sampai ke 
pengirimannya. Sehingga permasalahanpermasalahan diawal dapat teratasi dan semoga dapat meningkatkan omset penghasilan.

Pelaku UMKM yg ingin memasarkan produknya pada sistem dapat mengunjungi websitenya di http://masar.sigerinstitut.com, lalu melakukan pendaftaran sebagai penjual dengan mengisi form biodata yg disediakan dengan lengkap dan asli, setelah selesai melakukan pendaftaran pelaku umkm akan di berikan hak akses penjual dan sudah dapat mulai memasarkan hasil umkmnya. Untuk konsumen yg akan membeli hasil umkm dapat mengunjungi website sistem, lalu melakukan pendaftaran sebagai pembeli dengan mengisi form biodata yg di sediakan dengan lengkap dan asli, setelah melakukan pendaftran konsumen akan di berikan hak akses pembeli, dan sudah dapat melakukan proses transaksi pembelian barang atau jasa hasil UMKM. Dan selain sistem penelitian ini juga menghasilakan laporan penelitian yang menerangkan mulai tahap analisa dan ke perancangan yang terperinci dan dapat dikembangkan lebih lanjut.

Sehingga dalam pembahasan ini akan menerangkan tentang hasil dari perancangan sistem pemasaran online hasil UMKM beserta bagaimana sistem atau website ini bekerja, dengan memberikan contoh tampilan sistem. Dimana sistem siap dengan sebenarnya, sehingga dapat diketahui apakah sistem yang dihasilkan mampu menghasilkan benar-benar tujuan yang direncanakan.

\subsection{Halaman Utama Awal (penjual,pembeli)}

Saat pertama mengakses sistem, yang akan ditampilkan adalah halaman utama sistem. Pada halaman utama, pengguna bisa melihat barang yang ada tapi tidak bisa memesannya pengguna baru perlu menjadi member disistem untuk bisa melakukan transaksi. Bagi yang sudah menjadi member, pengguna hanya perlu melakukan login, dan jika belum bisa mendaftar.

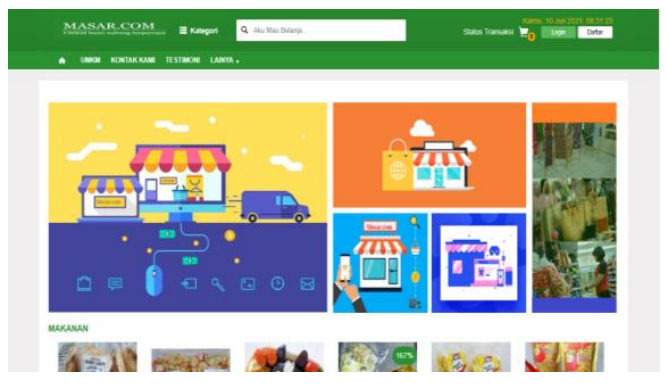

Gambar 4 Halaman Utama Awal

\subsection{Halaman Daftar}

Halaman Daftar ini sekaligus ada dua form yaitu form daftar untuk pembeli dan penjual, dibawah adalah tampilan untuk form registrasi atau pendaftaran pembeli. Jika pembeli ingin memiliki akses sebagai member dalam sistem, pengguna perlu melakukan pendaftaran dan memasukkan data-data yang diperlukan sesuai KTP.

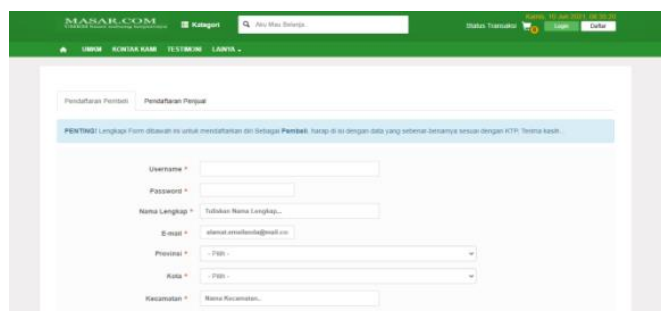

Gambar 5 Halaman Daftar

\subsection{Halaman Login}

Jika pengguna memilih menu login akan muncul tampilan seperti diatas. Halaman login ini sekaligus berisi form login pembeli dan penjual, pengguna hanya perlu memasukkan username dan password yang sudah didaftarkan. Setelah berhasil melakukan login pengguna akan diarakan kemenu utama masing-masing user.

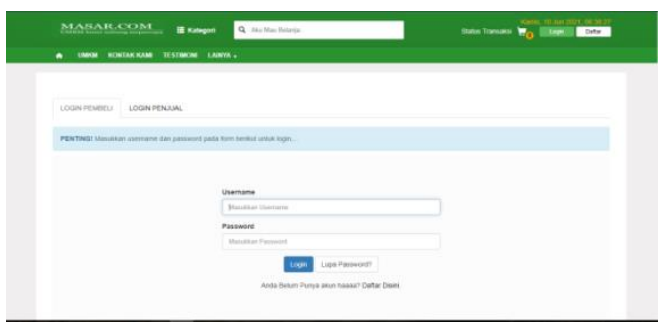

Gambar 6 Halaman Login 


\subsection{Halaman Detail Produk}

Setelah melihat sekilas produk di halaman home dan tertarik pada produk dan mengkliknya maka akan di arahkan pada halaman detail produk dan halaman pembelian seperti di atas. Pada halaman ini di sajikan detail produk dapat menghubungi penjual untuk bertanya dan bernego, menentukan jumlah produk yg akan dibeli dan melakukan pembelian.

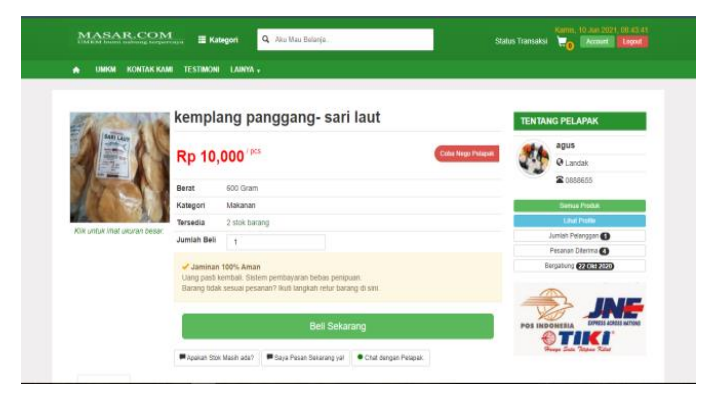

Gambar 7 Halaman Detail Produk

\subsection{Halaman Keranjang}

Setelah melihat detail barang dan menentukan jumlah yg di beli dan pembeli menekan tombol beli sekarang maka akan barang akan dimasukan ke keranjang belanja seperti diatas, pembeli dapat membatalkan transaksi disini, jika tidak pembeli menentukan metode pengiran dan melakukan transfer pembayaran sesuai nomer rekening yg di berikan.

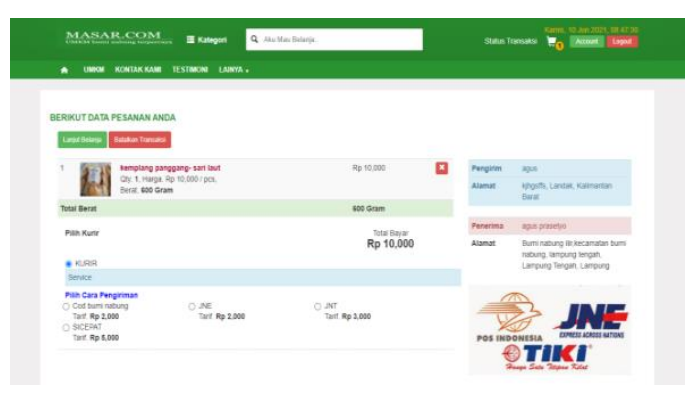

Gambar 8 Halaman Keranjang

\subsection{Halaman Status Transaksi}

Pembeli akan diarahkan kehalaman status transaksi, untuk pesanan dengan status pending artinya pembeli belum melakukan konfirmasi pembayaran maka sebaiknya pembeli melakukan transfer ke rekening sesuai yang di berikan dan melakukan konfirmasi pembayaran dengan menekan tombol konfirmasi, untuk pesanan dengan status konfirmasi artinya sudah terkonfirmasi pembayarannya, dan menunggu penjual untuk memproses barang, untuk pesanan dengan status proses berarti pesanan sedang di proses atau dikirim, dan selesai untuk pesanan yang sudah selesai.

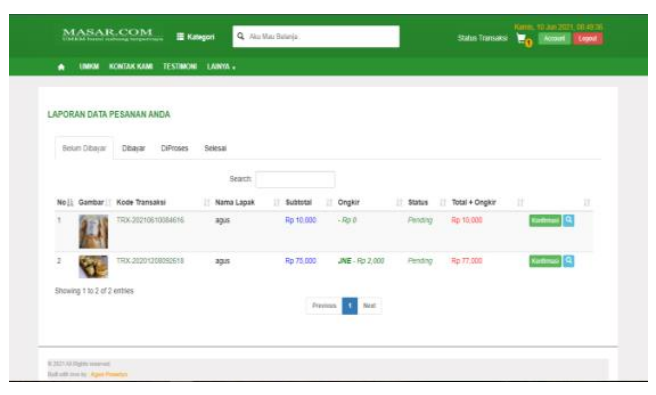

Gambar 9 Halaman Status Transaksi

\subsection{Halaman Konfirmasi Bayar}

Jika anda sudah melakukan transfer pembayaran, lalu dari halaman status transaksi pilih pesanan yg sudah di bayar dan klik konfirmasi, maka akan di arahkan ke halaman konfirmasi pembayaran dengan mengisi nama pengirim dan melampirkan bukti transfer dan klik kirimkan,maka status pesanan akan berubah menjadi terkonfirmasi, dan menunggu proses dari penjual.

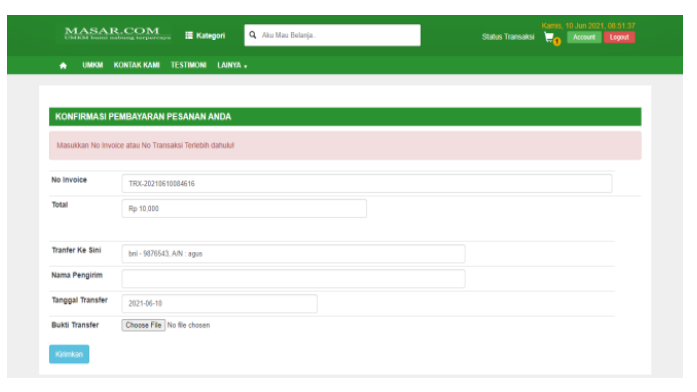

Gambar 10 Halaman Konfirmasi Bayar

\subsection{Halaman Utama Penjual}

Setelah penjual berhasil login maka akan di arahkan pada menu utama penjual yg menampilkan profil penjual dan bisa mengedit profil dan toko lapak anda untuk melihat tampilan toko anda, menampilkan 10 transaksi penjualan trakhir dan untuk lebih lengkapnya klik lihat semua, menampilkan hasil total penjualan, dan hasil produk pribadi,serta beberapa menu yaitu referensi untuk mengatur 
lapak (produk, cod, serta lapak), transaksi untu manajemen transaksi (orderan konsumen, pembayaran konsumen), laporan untuk melihat keuangan, edit profil untuk mengedit profil, logout untuk keluar.

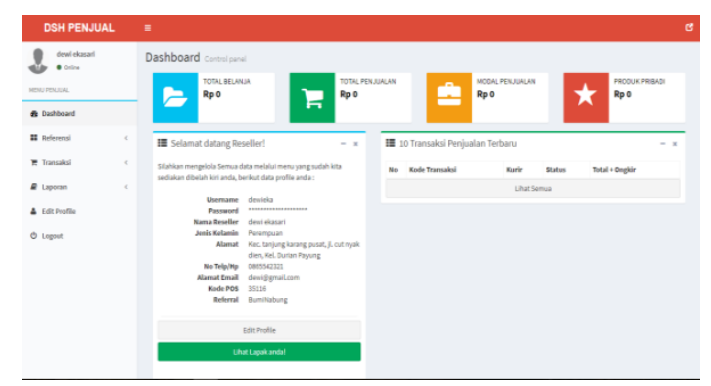

Gambar 11 Halaman Utama Penjual

\subsection{Halaman Data Produk Penjual}

Untuk melakukan manajemen produk jualan penjual dapat memilih menu referensi, sub menu data produk anda, maka akan di tampilkan halaman data produk penjual seperti di atas di sisni penjual dapat dapat menambahkan data produk jualan baru, serta dapat mengedit ataupun menghapus data produk yg sudah ada.

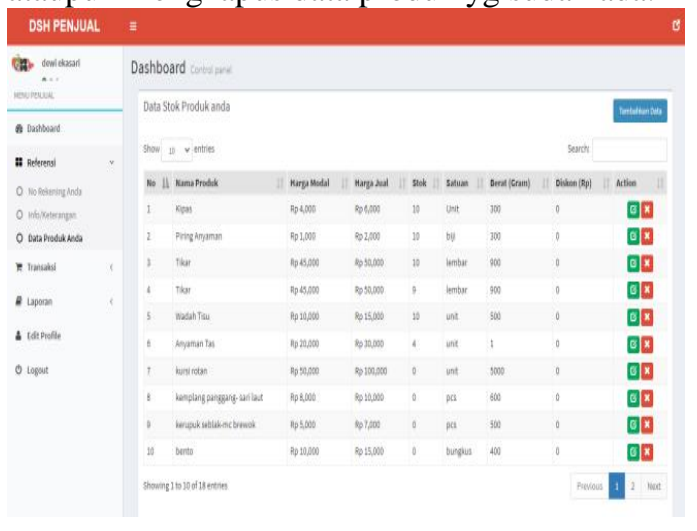

Gambar 12 Halaman Data Produk Penjual

\subsection{Halaman Data Orderan}

Untuk melihat orderan dari pembeli, penjual dapat melihat menu transaksi dan sub menu penjualan ke konsumen, maka akan di tampilkan ke halaman data transaksi penjualan atau orderan dari konsumen seperti di atas, dihalaman ini penjual dapat melihat orderan dari pembeli atau transaksi yg sudah di terima dan statusnya, pada halaman ini penjual dapat melihat orderan dari pembeli dan detailnya.

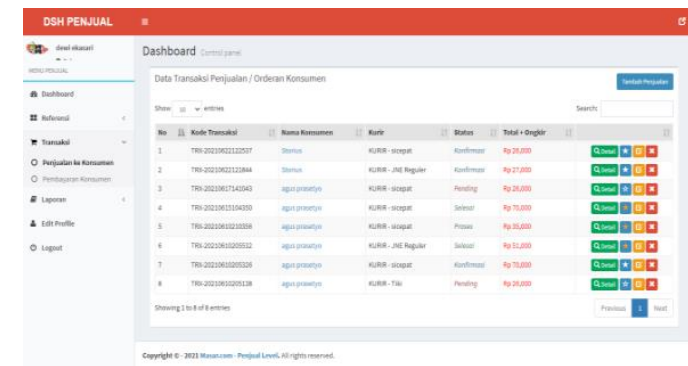

Gambar 13 Halaman Data Orderan

\subsection{Halaman Data Pembayaran}

Untuk melihat bukti pembayaran dari pembeli, penjual dapat melihatnya dari menu transaksi dan sub menu pembayaran konsumen maka akan di tampilkan halaman data konfirmasi pembayaran dari pembeli seperti di atas, di halaman ini penjual dapat melihat bukti pembayaran dan detailnya dengan mengklik kode transaksi, dan penjual dapat mendownload bukti transfer untuk bukti bayar dan untuk lebih menindak lanjuti pesanan konsumen tersebut.

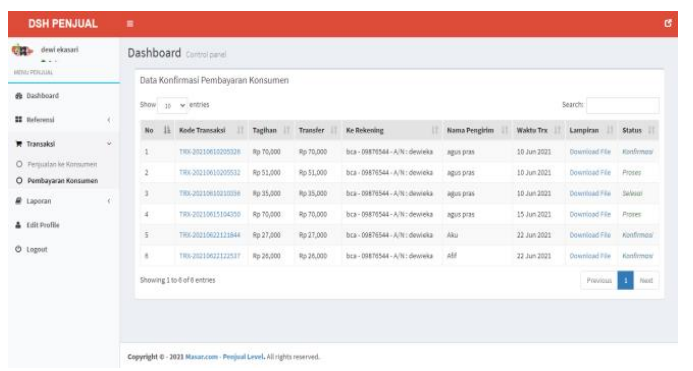

Gambar 14 Halaman Data Pembayaran

\subsection{Output Struk Beli (Pembeli)}

Dibawah ini adalah struk beli atau detail pesanan, halaman ini dapat di akses dari menu status transaksi, dan pilih detail pada pesanan yg akan dilihat detailnya, lalu cetak struk.

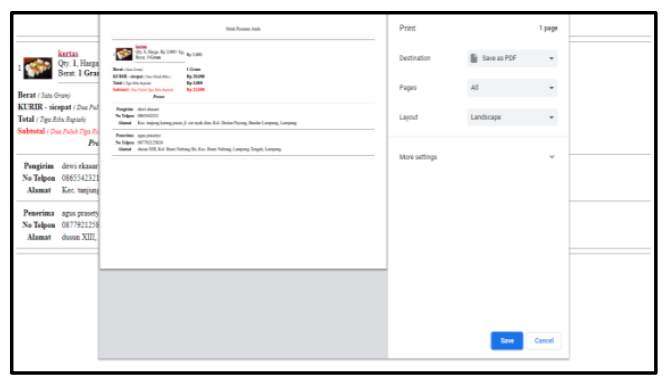

Gambar 15 Output Struk Beli 


\subsection{Output Detail Orderan (Penjual)}

Dibawah ini adalah output detail orderan masuk, penjual dapat melihat detail orderan masuk pada menu transaksi sub menu penjualan konsumen, dan memilih orderan masuk yg akan dilihat detailnya dengan klik detail.

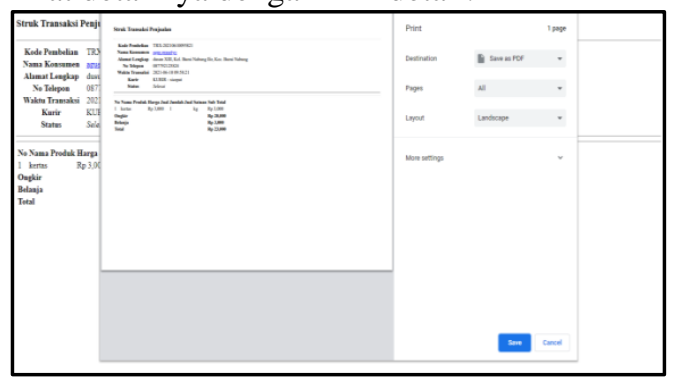

Gambar 16 Output Detail Orderan

\subsection{Output Laporan Data Keuangan}

Halaman keuangan adalah halaman yg memuat hasil penjualan dari dari total keseluruhan, modal dan keuntungan, serta menyertakan barang apa saja yg terjual,halaman ini dapat di akses pada menu laporan.

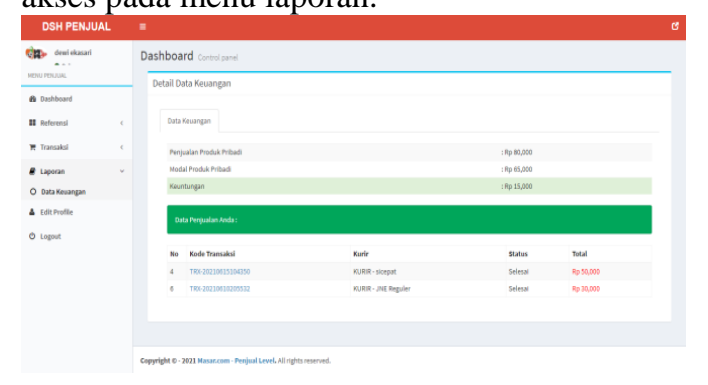

Gambar 17 Output Laporan Data Keuangan

\section{KESIMPULAN}

Berdasarkan semua tahapan penelitian yang telah dilakukan mulai dari tahap penganalisaan baik permasalahan dan solusi yang akan diambil, serta telah dilakukanya perancangan dan pembuatan sistem sesuai permasalahan pemasaran produk UMKM terkait sehingga menghasilkan sebuah sistem pemasaran produk UMKM berbasis web dan karya tulis ilmiah yg menerangkan dengan rinci analisa dan perancangan sistemnya, dapat ditarik beberapa kesimpulan yaitu :

1. Dengan adanya sistem pemasaran produk UMKM berbasis web ini dapat menjadi solusi dari permasalahanpermasalahan yang telah didefinisikan diawal dan dapat meningkatkan omset penjualan para pelaku UMKM terkait sehingga tujuan dari penulisan dan perancangan penelitian ini dapat terwujud.

2. Dapat di simpulkan bahwa pemanfaatan media internet dalam kegiatan pemasaran dan penyebar luasan informasi mengenai produk-produk yg di jual masyarakat sangat bermanfaat dan memenuhi strategi pemasaran online, sehingga lebih mudah menjangkau pasar yg lebih luas, lebih efisien dan efektif. Dalam penerapanya dapat berupa E-Commerce, $E$ Marketplace, sistem pemasaran online dan lainya.

3. Penggunaan metode pengembangan sistem sangat tepat diterapkan untuk melakukan pembuatan sistem yang kompleks, karena dalam setiap tahapanya jelas terdefinisi, dan tidak ada intervensi dari tujuan awal.

\section{PUSTAKA}

[1] Krismiaji, 2015, Sistem Informasi Akuntansi, Unit Penerbit, Yogyakarta.

[2] Anggun Nugroho. 2015. Perancangan Sistem Informasi Pengelolaan Aset Ukm STMIK STIKOM Bali Berbasis Client Server, vol 2, No. 1, STMIK STIKOM Bali, Bali, hal. 1-7.

[3] Ali Hasan, 2015. Marketing, Yogyakarta : Media Pressindo.

[4] Kotler, Philip and Gary Amstrong. 2018. Principles of Marketing, 17th Ed, Global Edition Pearson Education, New Jersey.

[5] Haryantini, Agra Sadya., 2019. Sistem Informasi Pemasaran, Banten :Unpam Press.

[6] Kesuma, C., \& Rahmawati, L. 2017. Sistem Informasi Akademik Berbasis Web Pada SMK Purnama 2 Banyumas. Indonesian Journal on Networking and Security, Vol 7(No 3), hal. 1-9. 
[7] A Tedyyana, R Kurniati, 2016. Membuat Web Server Menggunakan Dinamic Domain Name System Pada Ip Dinamis, Vol 7,No. 1, Jurnal Teknologi Informasi dan Komunikasi, hal. $1-10$.

[8] Anggraeni, Elisabet Yuniati dan Rita Irviani, 2017. Pengantar Sistem Informasi, Andi, Yokyakarta.

[9] M Alda. 2021. Rekayasa Perangkat Lunak Berorientasi Objek.

Bandung : Media Sains Indonesia.

[10] Syafitri, Y. (2015). Pemanfaatan Media Internet untuk Memperkenalkan Produk Kerajinan Tangan pada Home Industri Kain Flanel Lampung Selatan. Jurnal EXPERT, 5(2). Retrieved from http://jurnal.ubl.ac.id/index.php/ expert/article/view/721 